\title{
Strategic Approach of Saudi Small and Medium-Sized Enterprises: More of Emergent or Deliberate?
}

\author{
Mutab Z Alenzy ${ }^{1}$ \\ ${ }^{1}$ College of Business Administration, Taibah University, Saudi Arabia \\ Correspondence: Mutab Z Alenzy, College of Business Administration Taibah University, Janadah Bin Umayyah \\ Road, Tayba ‘Tayba, Medina 42353, Saudi Arabia.
}

Received: January 8, 2018

Accepted: February 6, 2018

Online Published: February 12, 2018

doi:10.5539/ibr.v11n3p110

URL: https://doi.org/10.5539/ibr.v11n3p110

\begin{abstract}
The impact of the strategic planning, especially in promising economies are significant indicators of success for the small and medium-sized enterprises (SMEs). Globally, the SMEs sector suffers from a very high failure rate and the most important reason for this is poor capacity in strategic management. The practice of SMEs in unstable environments, especially in oil-based economy like Saudi Arabia (SA), creates the need for more flexibility in building strategies. Therefore, as the aim of this study was to structurally examine the type of strategic management in SMEs, the adaptation of a high flexibility strategic theoretical framework based on the emergent strategy model by Mintzberg might be more suitable for SMEs' needs and capabilities. In this research, forty-six SMEs were surveyed in SA. Unlike most previous research, whose variables focused on external issues (such as funding issues or government policies), this study focuses on internal issues (such as internal capabilities) that influence the choice of strategy in SMEs. Correlation and factor analysis were used because the data set was appropriate for factor analysis as the KMO value was greater than 0.50 . The research concluded that SMEs tend to adopt a deliberate strategy more than the emerging strategy.
\end{abstract}

Keywords: deliberate, emergent, organizational structure, strategic management, small and medium-enterprises, Saudi Arabia

\section{Background}

Strategic management (SM) has turned out to be a fundamental practice that can improve organizational performance (Andrews et al. 2006; Boyne 2006). Bracker et al. (1988) also stressed that SM is a series of actions aimed at defining topics, objectives, and decision-making. In addition, the strategy formulation is often regarded as a continuous series of procedures that adapts and corrects itself according to external conditions (Kraus 2007). Moreover, Milutinovic et al. (2015) have explained a concept of strategic as it has significant impact on competitiveness, creation of growth strategies, new product categories and business models, as well as on changing the way of the business management. In addition, because of the nature of SMEs which characterized by lack of stability due to lack of resources, creating a clear vision for their strategic plan becomes extremely difficult especially in unstable environment (Gioia et al., 2012; Huy et al., 2014). Literature has discussed two types of strategies: deliberate and emergent.

A deliberate strategy is referred to as a strategy that's cautiously scheduled and organized by the firm. These are a conventional mode of strategies, as an idea is articulated and a plan is augmented around it followed by suitable action. The reason behind the adaption of this strategy is the development of long-term sustainability, resulting in a competitive advantage for the company (Eisenhardt and Brown 1998; Mintzberg and Waters 1985), with a focus on the strategic management statement to reflect the prominence of balanced strategy development (Mintzberg and Waters, 1998).

On the other hand, an emergent strategy is basically an unplanned approach where the sequence of action is perceived as strategic after its occurrence (Bozkurt \& Kalkan, 2013). The emergent approach demonstrates the improbability that ascends during the strategy development phase in diverse environments (Mintzberg and Waters, 1985). In the highly competitive environment today, the adoption of emerging strategies has become a necessity and will ensure the adaptation and survival for the companies (Chari et al., 2014; Whittington et al., 2017). 
Previous studies from Quinn (1978), as well as a study from Mintzberg (1978), have argued that the strategy-making process is an emergent and dynamic procedure and that strategic plans should evolve according to the results and the changes in the internal and external environment of the organisation (Gibbons and O'Connor, 2005). Similarly, Stonehouse and Pemberton (2002) noted that the emergent approach to strategy is a better fit in dynamic and uncertain environments but does not imply a complete absence of strategic orientation. In their study, Mintzberg and Waters (1998) viewed strategy formulation as an evolving and learning procedure and Quinn (1980) noted that the emergent approach considers the instability of the environment and allows managers to make changes to the business strategy at any time, according to the information they have access to. Evaluating the emergent approach to strategy formulation, Mintzberg and Waters (1998) outlined the dearth of rules and regulations on how strategy should be formulated; instead, it illustrates how strategy is formulated. Also, the deliberate and emergent strategies are mutually significant for a firm as the deliberate approach highlights the direction and devises the probable outcome, while the emergent approach relies on strategic learning (Mintzberg and Waters 1985; Mirabeau and Maguire, 2014).

There is also a wholesome deliberate strategy, which is one where, after the selection of an approach, all actions are geared towards the realisation of that plan. As evident, emergent strategy lacks initial objective, but with time it becomes dependable. It is well-matched with SMEs as the reflexive nature chains the productivity of organisations at this level. The contrast manifested between both strategies is evident via certain studies in the subjected field. It has to be considered that strategy origination and organisation is a varying and diverse practice, which often leads to the mutual existence of both strategies.

\subsection{Scope of the SMEs in Saudi Arabia}

SMEs sector is vital for economic growth, social development, employment and job creation. Therefore, it is a recognised fact throughout the world that the performance of this sector is closely linked to the economic performance of the country. It can be argued that SMEs sector have the potential to unlock all these benefits for the SA economy because it is a fast-moving sector in SA (Achoui, 2009). According to Oxford Business Group (2015), the SMEs account for around 90\% of registered businesses in SA and the sector alone absorbs 75\% of the total workforce in SA (Lonial and Carter, 2015). Although there has been considerable support in recent years for the private sector by the government of SA (Alonazi, 2017) as well as according to the G20 Research Group (2016), the privet sector performance and specially the SMEs considered very low. Moreover, according to the World Trade Organization (2016), the median contribution of SMEs to GDP and economic growth in the world is $45 \%$ as $49 \%$ in developed countries, $35 \%$ in developing countries, while is SA the GDP contribution of SMEs is just $20 \%$. The present situation calls for expediting the strategy development procedures into SMEs through authenticated means (Cagliano et al., 2001). The available literature in this domain clearly illustrates the significance of strategy management in SMEs for prolonged sustainability in the market via exploration of novel paths for a firm's survival in a dynamic state (Berry, 1998). The decision-making procedures, thus practiced in SMEs are often characterised as dysfunctional and unsystematic (Dean, 1986). Small enterprises, particularly in SA, lack the strategic perspective of firm's dynamic procedures for sustainable growth (Bamberger, 1982). A survey of Alotaibi and Hana exposed the fact that lack of finance and an effective strategy-making process are major obstacles towards the success of SA SMEs and, in spite of the realisation of the potential benefits related to strategic management, they are not adopted by small firms in SA (2015).

According to the Small and Medium Enterprises General Authority (SMEA) (SMEA, 2016) the SMEs are defined based on two considerations: the number of employees and their income in SA.

Table 1. Definition of Micro, Small, and Medium Enterprises in SA (SMEA, 2016) **

\begin{tabular}{lll}
\hline Type of Enterprise & Number of Employees & Annual Income (in million Saudi riyals) \\
\hline Micro & $1 \geq 5$ & Less than 3 \\
Small & $3 \geq 50$ & $3 \geq 50$ \\
Medium & $51 \geq 249$ & $51 \geq 200$ \\
Large & 250 or more & 201 or more \\
\hline
\end{tabular}

*1 Saudi Riyal equal usually to 0.26 US Dollar

**In the absence of income data, the number of full-time employees is the standard

As shown in the table 1, the SMEs in SA divided into three types: micro, small and medium enterprises. With micro companies, the number of employees is between 1 and 5 and the annual income is 3 million or less SA riyals. With small companies, the number of employees between 3 and 50 million SA riyals. With medium companies, the number of employees is between 51 and 249 and annual income is between 51 and 200 million in SA riyals. 
In the last few years, there has been a focus on the findings of the linkage between the performance of SMEs and strategic management (Borch and Madsen, 2007). Fixed performance has a direct relationship to the firm's strategic management (Jantunen et al., 2005; Borch and Madsen, 2007). On the other hand, there were some studies that did not find this relationship, such as Smart and Conant (1994) which may be because of the standards followed in those studies, which were based on targeting the growth and profit only (Covin and Slevin, 1989; Wiklund, 1999; Avlonitis and Salavou, 2007).

In addition, Retha Wiesner and Bruce Millett (2012) have explored 1,230 Australian SMEs to figure out the nature and prevalence of strategic practices among them and to ascertain to what extent firm size differentiates the patterning and prevalence of strategic practices. They found that the SMEs in Australia use more of a deliberate approach to strategy-making. Finally, Bozkurt and Kalkan (2013) examined 192 SMEs in Turkey to find out if they adopt more unconscious actions or deliberately planned patterned behaviour (PPB) to guide their actions in their strategies. They found that SMEs adopt more deliberate strategies than emergent strategies. Covin and Slevin (1989) differentiate formal planned strategy formation and the informal emergent strategy formation in their survey of SMEs in unfriendly and friendly environments. The outcome was that no direct linkage was found between firm strategy formation and its performance. However, once organisation structure is added as an interviewing variable, the outcomes are more useful.

In summary, the range of SMEs in general and SA in particular has not been covered from the point of view of strategic management, except to a limited extent and sometimes we find inconsistencies in research results (Soininen et al., 2012, p. 614). This research is a contribution to the knowledge of the strategic directions of SMEs in SA, which will remove some of the blurring of this important sector in relation to the science of management strategies. Thus, primary objective of this study is to identify that SMEs could be categorised as either emergent or deliberate in their strategic approaches.

\section{Method}

\subsection{Design}

A quantitative methodology is consistent with this objective. The choice of a positivist paradigm is the directional outlook of research towards the type of results it will produce. In addition, a quantitative research approach standardises the utilisation of a deductive scheme, thus giving proper orientation to the procedure. The quantitative research aligns with focused (deductive) study and qualitative research revolves around an exploratory domain (inductive). The elementary objective behind current study, entailing the practices of strategic management in SA SMEs, calls for deduction from available data and information. As per subscribed circumstances, the current study is deductive in nature, employing scientific evidence to formulate a theory.

\subsection{Subjects}

This research has used various sectors of SMEs' executive managers in SA and they were contacted electronically and encouraged to participate in this research. Seventy SMEs were emailed to participate in this study. In this survey, all participants had to be adult employees to participate. The respondents were selected from the mid and top-level hierarchies of SMEs operating in SA. Companies were communicated with through their official email and requested to collaborate in the survey.

\subsection{Tool and Data Collection Method}

The data has been collected using a survey questionnaire developed by Slevin and Covin (1997). In this survey, an emergent and deliberate scale were developed for participants (questions: 11-15) and mechanistic and organic structure was formulated for the responses of a few questions (17-18). In addition, the reliability coefficients were tested in this research.

All companies were selected based on a rating of the SMEA and any company that does not comply with these criteria was excluded from the research. We also excluded SMEs that have been working actively for less than 4 years, to ensure that these projects have sufficiently exercised strategic practices and are able to differentiate between deliberate and emerging strategy. For example, the nature of emerging strategic management is based on learning from mistakes and often these SMEs will not be able to learn from their experiences with less than four years of continuous work.

\subsection{Data Analysis}

The data analysis was carried out via an SPSS 24. First, descriptive analysis was used; followed by functional analysis to explore the relation between the constructs in each domain. Subsequently, there is a dual considerable choice with respect to research methodology, experimental and survey (Creswell, 2013). Survey research, 
distributes a quantitative sketch of details in a given populace via longitudinal arrangement, while simplifying the progress from the small sample to a larger populace (Creswell, 2013). The new enterprise policy that could be utilised is experimental design that inclines to place few conditional constraints on one group and witness the outcome while concealing the same from the other group. This strategy could not be employed in our study as our current research is grounded in prevailing tendencies that can be observed through survey.

\section{Analysis and Findings}

In terms of measurements, this research used the scale of the strategy of emergent-to-deliberate which developed by Slevin and Covin (1997). Besides, the five items, 7-point scale was used to measure the type of strategy formation pattern. Furthermore, to measure the mechanization of SMEs structures, this research used the organization structure scale with the seven items, 7-point scale.

Table 2 shows the basic characteristics of SMEs involved in the research.

Table 2. Descriptive Statistics for SMEs

\begin{tabular}{lll}
\hline F/P & Frequency & Percentage \\
\hline Firm Type: & & \\
Production & 5 & $10.9 \%$ \\
Service & 30 & $66 \%$ \\
Trade & 11 & $22.9 \%$ \\
Size: & 18 & $39.1 \%$ \\
Micro & 21 & $45.7 \%$ \\
Small & 7 & $15.2 \%$ \\
Medium & & \\
Age: & 16 & $34.8 \%$ \\
4-6 years (Low) & 30 & $65.2 \%$ \\
7 or more (High) & & \\
Management Level: & 18 & $39.2 \%$ \\
General Manager & 1 & $2.2 \%$ \\
Finance & 5 & $10.6 \%$ \\
Marketing & 18 & $39.2 \%$ \\
Founder & 2 & $4.4 \%$ \\
HR Director & 1 & $2.2 \%$ \\
Quality Manger & 1 & $2.2 \%$ \\
Public Relationship Manger & & \\
Existence of Strategic Plan: & 42 & $91.3 \%$ \\
Yes & 4 & $8.7 \%$ \\
No &
\end{tabular}

Out of seventy SMEs, only 46 subjects were suitable for data analysis. Table 2 shows the descriptive statistics, which is, include all the basic elements of the data as well as the value of each element.

Table 3 shows the reliability of the tool used in this study.

Table 3. The reliability coefficients for variables

\begin{tabular}{lll}
\hline Variables & Number of Items & Cronbach's Alpha \\
\hline Organizational Structures & 7 & .854 \\
Strategies & 5 & .744 \\
\hline
\end{tabular}

In table 3, the result of Alpha Cronbach coefficients was accepted because it was higher than 0.50. According to the Nunnally (1978) the Alpha coefficients can be accepted if they were higher than 0.70. As well as according to Bagozzi and Yi (1988), and he Alpha coefficients can be accepted if they were higher than 0.50.

\subsection{Strategy}

To assess the various factors associated with the strategic used in the SMEs, table (4) shows the constructs of each variable.

Table 4. Total Variance Explained for Strategies

\begin{tabular}{|c|c|c|c|c|c|c|c|c|c|}
\hline \multirow{3}{*}{$\begin{array}{l}\text { Component } \\
1\end{array}$} & \multicolumn{2}{|c|}{ Initial Eigenvalues } & & \multicolumn{2}{|c|}{$\begin{array}{l}\text { Extraction } \\
\text { Loadings }\end{array}$} & \multicolumn{2}{|c|}{$\begin{array}{rr}\text { of } & \begin{array}{r}\text { SquaredRotation } \\
\text { Loadings }\end{array} \\
\end{array}$} & Sums & \multirow{2}{*}{$\begin{array}{l}\text { of Squared } \\
\text { Cumulative \% }\end{array}$} \\
\hline & $\mathrm{T}$. & $\%$ of $\mathrm{V}$ & Cumulative $\%$ & $\mathrm{~T}$. & $\%$ of $\mathrm{V}$ & Cumula & $6 \mathrm{~T}$. & $\%$ of $\mathrm{V}$ & \\
\hline & 2.494 & 49.872 & 49.872 & 2.494 & 49.872 & 49.872 & 2.037 & 40.746 & 40.746 \\
\hline 2 & 1.224 & 24.482 & 74.353 & 1.224 & 24.482 & 74.353 & 1.680 & 33.607 & 74.353 \\
\hline 3 & .547 & 10.950 & 85.303 & & & & & & \\
\hline 4 & .464 & 9.276 & 94.579 & & & & & & \\
\hline 5 & .271 & 5.421 & 100.000 & & & & & & \\
\hline
\end{tabular}


*V=Variance; $\mathrm{T}=$ Total

The cumulative percent in rotation sums of squared loadings is 74.353. As show in to the total variance explained for organizational structures (Table 4), the one factor resulted in factor analysis explained 74.353 percent of the total variance. As well as all communalities values are more than 0.50 .

To find the relation between basic variables of the SMEs, Pearson correlation was conducted as shown in table 5 .

Table 5. Pearson correlation values of the basic components of the SMEs

\begin{tabular}{|c|c|c|c|c|c|}
\hline \multicolumn{2}{|c|}{ Data $(n=46)$} & Strategy & Structure & Size & Age \\
\hline \multirow[t]{2}{*}{ Strategy } & Pearson Correlation & 1 & $.663^{* *}$ & -0.278 & $-.337^{*}$ \\
\hline & Sig. (2-tailed) & & 0.000 & 0.061 & 0.022 \\
\hline \multirow[t]{2}{*}{ Structure } & Pearson Correlation & & 1 & -0.229 & -0.178 \\
\hline & Sig. (2-tailed) & & & 0.127 & 0.236 \\
\hline \multirow[t]{2}{*}{ Size } & Pearson Correlation & & & 1 & $.535^{* * *}$ \\
\hline & Sig. (2-tailed) & & & & 0.000 \\
\hline Age & $\begin{array}{l}\text { Pearson Correlation } \\
\text { Sig. (2-tailed) }\end{array}$ & & & & 1 \\
\hline
\end{tabular}

**. Correlation is significant at the 0.01 level (2-tailed).

*. Correlation is significant at the 0.05 level (2-tailed).

In this research, the strategy of the companies was categorized by two continuums: the deliberate strategy and the emergent strategy. By using the six items, 7-point scale to measure the construct of strategy formation pattern of the company so we can identify the type of the strategy. As the higher grades in this scale mean that the company adopts the deliberate strategy and in contrast, if the company achieved lower grades in the scale, this means that the company uses the emergent strategy.

In order to verify the relationships between both the adopted and emerging strategies, the organizational structure (mechanistic and organic), the age of the company and the size of the company, the Pearson correlation was used as shown in Table 5. In addition, one to one relationship in the correlation table between the dependent variables and independent variables is in the value of Pearson correlation coefficients.

As shown in Table 5, the second issue (Strategy is positively connected to the organizational structures) is a valid issue as the pattern of strategy formation and structure of the company. There is no positive relationship between the deliberate strategy with the age of the company $(-0.278)$. However, there is a weak negative correlation between deliberate strategy and company size $\left(-.337^{*}\right)$.

\section{Discussion}

In this study, quantitative research methods were used with a questionnaire on a random sample of SMEs in SA. This study aims to explore the trends of the relationship between the strategic direction of SMEs in SA (deliberate strategies or emerging strategies) and the organisational structures in SA SMEs.

The first issue of the research focuses on showing the descriptive direction of SMEs in relation to the strategic spread. Results suggested that the SMEs adopted more emergent strategies compared to deliberate strategies. From the data results we found that, for a total of 46 SMEs that were studied, $92 \%$ of the SMEs in SA adopted more of a planned strategy, while $9 \%$ seemed to use more of an emergent strategy.

\subsection{Deliberate and Emergent Strategies}

Although the result of this research, which proves that the majority of SMEs follow the deliberate approach, the results of this research came in line with much previous research. Stonehouse and Pemberton (2002) completed a study in the United Kingdom on the service and manufacturing sectors and they found that SMEs preferred analysis as a first step before making any important decisions and actions, which is the main point of view in the deliberate approach. Also, Wongsawan (2009), in his study of how contextual variables impact the process of formulating strategy, found that a positive relation impact happens between benign environments, the process of the planned strategy formation, the organisational structure of the mechanisms and friendly environments.

On the other hand, the result of our research contrasts with some studies whose results have concluded that SME strategies are radically different within large firms. Harris et al. (2000) highlighted that SMEs rely on personal relationships to make their own strategy, which is inherently emerging and adapted to the environment. While Verreynne (2006) assumes that there is no strategic mode of rationality for small businesses, Mazzarol and Reboud (2006, p. 263), as well as Mintzberg and Waters (1985) maintain that small businesses have an emerging approach and do not follow the planned and systematic approach. Therefore, SMEs offer a unique context for examining strategy approaches since they use a wide range of strategic behaviour. It can start from deliberate strategy and continue until becoming unintentionally emergent at the end (Leitner, 2014). 
The use of deliberate strategy in SMEs in SA is due to a weakness in the entrepreneurial culture among SA entrepreneurs. As most entrepreneurs attempt to avoid any risk as much as possible by adopting a traditional planning style. In addition, the majority of the strategic planners in SMEs are copying other projects, which is contrary to what characterizes the emerging strategic style, which stimulates innovation and the knowledge sharing among the firm.

\subsection{Organization Structure}

In the second issue in this study, we tested the relationship effect between the strategies and the organisational structure in SMEs. The results supported the conception of interactions in the SMEs between the strategy formation pattern and the structure of the company. Based on the search results, the processes of the formation of the deliberate strategy match the features of the mechanistic structure, while emerging strategic formation processes must be in line with organic structural characteristics. What distinguishes the mechanistic structures is that it tends to rely on strict policies and rules in order to move away from the uncertainty of strategies and administrative matters, which is in line with the strategic orientations of deliberate thinking. In the case of organic structures, they are characterised by adapting quickly to volatile situations because of high flexibility and this is consistent with the strategic directions in the emerging thinking.

As indicated earlier, previous studies have supported this position, such as Covin and Slevin (1997). Linking the mechanistic organisational structure with planned strategy is positively associated with the firm's growth; on the other hand, the organic organisational structure is positively linked with the emergent strategy. These outcomes indicate the impact of planned and emergent strategies as contingency variables on various performance results.

\section{Conclusions}

The aim of this study was to investigate the general trend of strategic management used in SA SMEs. The theoretical perspective used in this study was based on Mintzberg's emerging strategic methodology. In addition, an explanation was provided on the methodologies used in this research, as well as covering the previous studies and reviewing the literature. This research concluded that most of SA SMEs are using deliberate strategies rather than emergent strategies. One of the limitations of this study was related to the sample. For example, any firm operating less than four years has been excluded from the data. As well as the exclusion of any firm that is larger than the standards used to classify SMEs in SA, which were adopted in this research based on the SMEA standards. The research study suggests for further research focusing on the role of stakeholders in directing the SMEs with adopting the deliberate approach.

\section{Acknowledgements}

This research was supported by Taibah University and Saudi Culture Mission in Australia. I would like to express my very great appreciation to Dr. Wadi Alonazi for his comments that greatly improved the manuscript.

\section{References}

Achoui, M. M. (2009). Human resource development in Gulf countries: an analysis of the trends and challenges facing Saudi Arabia. Human Resource Development International, 12(1), 35-46. https://doi.org/10.1080/13678860802638826

Alonazi, W. B. (2017). Exploring shared risks through public-private partnerships in public health programs: a mixed method. BMC public health, 17(1), 571. https://doi.org/10.1186/s12889-017-4489-z

Alotaibi, M., \& Hana, J. (2015). Strategic Planning in Saudi SMEs: Case Studies in the Private Health Insurance Sector. Browser Download This Paper.

Andrews, R., Boyne, G. A., \& Walker, R. M. (2006). Strategy content and organizational performance: An empirical analysis. Public Administration Review, 66(1), 52-63. https://doi.org/10.1111/j.1540-6210.2006.00555.x

Authority, (2016). The Small \& mdium enterprises identify.

Avlonitis, G. J., \& Salavou, H. E. (2007). Entrepreneurial orientation of SMEs, product innovativeness, and performance. Journal of Business Research, 60(5), 566-575. https://doi.org/10.1016/j.jbusres.2007.01.001

Bagozzi, R. P., \& Yi, Y. (1988). On the evaluation of structural equation models. Journal of the academy of marketing science, 16(1), 74-94. https://doi.org/10.1177/009207038801600107

Bamberger, I. (1982). Portfolio analysis for the small firm. Long Range Planning, 15(6), 49-57. https://doi.org/10.1016/0024-6301(82)90007-3

Berry, M. (1998). Strategic planning in small high tech companies. Long Range Planning, 31(3), 455-466. 
https://doi.org/10.1016/s0024-6301(98)80012-5

Borch, O. J., \& Madsen, E. L. (2007). Dynamic capabilities facilitating innovative strategies in SMEs. International Journal of Technoentrepreneurship, 1(1), 109-125. https://doi.org/10.1504/ijte.2007.014731

Bozkurt, Ö. Ç., \& Kalkan, A. (2013). Strategic focus in Turkish SMEs: emergent or deliberate strategies? Procedia-Social and Behavioral Sciences, 99, 929-937. https://doi.org/10.1016/j.sbspro.2013.10.566

Bracker, J. S., Keats, B. W., \& Pearson, J. N. (1988). Planning and financial performance among small firms in a growth industry. Strategic Management Journal, 9(6), 591-603. https://doi.org/10.1002/smj.4250090606

Chari, S., Katsikeas, C. S., Balabanis, G., \& Robson, M. J. (2014). Emergent marketing strategies and performance: The effects of market uncertainty and strategic feedback systems. British Journal of Management, 25(2), 145-165. https://doi.org/10.1111/j.1467-8551.2012.00843.x

Covin, J. G., \& Slevin, D. P. (1989). Empirical relationship among strategic posture environmental context variables, and new venture performance. Frontiers Entrepreneurship Research, 16(5), 124-133.

Creswell, J. W. (2013). Research design: Qualitative, quantitative, and mixed methods approaches: Sage publications.

Dean, B. V. (1986). The project-management approach in the "systematic management" of innovative start-up firms. Journal of business venturing, 1(2), 149-160. https://doi.org/10.1016/0883-9026(86)90011-x

Eisenhardt, K. M., \& Brown, S. L. (1998). Competing on the edge: Strategy as structured chaos. Long Range Planning, 31(5), 786-789. https://doi.org/10.1016/s0024-6301(98)00092-2

Gibbons, P. T., \& O'Connor, T. (2005). Influences on strategic planning processes among Irish SMEs. Journal of Small Business Management, 43(2), 170-186. https://doi.org/10.1111/j.1540-627x.2005.00132.x

Gioia, D. A., Nag, R., \& Corley, K. G. (2012). Visionary ambiguity and strategic change: The virtue of vagueness in launching major organizational change. Journal of Management Inquiry, 21(4), 364-375. https://doi.org/10.1177/1056492612447229

Group. (2016). Growth strategy of Saudi Arabia. Retrieved from

Group. (2015). The Report: Saudi Arabia (9781910068397). Retrieved from https://books.google.com.au/books?id=WCa-DQAAQBAJ

Harris, S., Forbes, T., \& Fletcher, M. (2000). Taught and enacted strategic approaches in young enterprises. International Journal of Entrepreneurial Behavior \& Research, 6(3), 125-145. http://www.emeraldinsight.com/doi/abs/10.1108/13552550010346217

Huy, Q. N., Corley, K. G., \& Kraatz, M. S. (2014). From support to mutiny: Shifting legitimacy judgments and emotional reactions impacting the implementation of radical change. Academy of Management journal, 57(6), 1650-1680. http://amj.aom.org/content/57/6/1650

Jantunen, A., Puumalainen, K., Saarenketo, S., \& Kyläheiko, K. (2005). Entrepreneurial orientation, dynamic capabilities and international performance. Journal of International Entrepreneurship, 3(3), 223-243. https://doi.org/10.1007/s10843-005-1133-2

Kraus, S. (2007). Strategic planning in new ventures and young SMEs. 21st Century Management-A Reference Handbook, 73-81. https://doi.org/10.4135/9781412954006.n8

Lonial, S. C., \& Carter, R. E. (2015). The impact of organizational orientations on medium and small firm performance: A resource - based perspective. Journal of Small Business Management, 53(1), 94-113. https://doi.org/10.1111/jsbm.12054

Mazzarol, T., \& Reboud, S. (2006). The strategic decision making of entrepreneurs within small high innovator firms. International Entrepreneurship and Management Journal, 2(2), 261-280. https://doi.org/10.1007/s11365-006-8688-9

Milutinović, R., Stošić, B., \& Mihić, M. (2015). Concepts and importance of strategic innovation in SMEs: Evidence from Serbia. Management: Journal of Sustainable Business and Management Solutions in Emerging Economies, 20(77), 35-42. https://doi.org/10.7595/management.fon.2015.0030

Mintzberg, H. (1978). Patterns in strategy formation. Management science, 24(9), 934-948. https://doi.org/10.1287/mnsc.24.9.934

Mintzberg, H., \& Waters, J. (1998). Of strategies, deliberate and emergent. The strategy reader. Oxford: 
Blackwell, 20-34. https://doi.org/10.1007/978-1-349-20317-8_1

Mintzberg, H., \& Waters, J. A. (1985). Of strategies, deliberate and emergent. Strategic Management Journal, 6(3), 257-272. https://doi.org/10.1002/smj.4250060306

Mirabeau, L., \& Maguire, S. (2014). From autonomous strategic behavior to emergent strategy. Strategic Management Journal, 35(8), 1202-1229. https://doi.org/10.1002/smj.2149

Organization. (2016). World trade report. Retrieved from https://www.wto.org/english/res_e/booksp_e/world_trade_report16_e.pdf

Quinn, J. B. (1978). Strategic Change:" Logical Incrementalism.". Sloan management review, 20(1), 7-19.

Quinn, J. B. (1980). Strategies for change: Logical incrementalism: Irwin Professional Publishing. https://doi.org/10.2307/257320

Raffaella, C., Kate, B., \& Chris, V. (2001). Small firms under MICROSCOPE: international differences in production/operations management practices and performance. Integrated Manufacturing Systems, 12(7), 469-482. https://doi.org/10.1108/eum0000000006229

Slevin, D. P., \& Covin, J. G. (1997). Strategy formation patterns, performance, and the significance of context. Journal of management, 23(2), 189-209. https://doi.org/10.1177/014920639702300205

Smart, D. T., \& Conant, J. S. (1994). Entrepreneurial orientation, distinctive marketing competencies and organizational performance. Journal of applied business research, 10(3), 28. https://doi.org/10.19030/jabr.v10i3.5921

Soininen, J., Martikainen, M., Puumalainen, K., \& Kyläheiko, K. (2012). Entrepreneurial orientation: Growth and profitability of Finnish small-and medium-sized enterprises. International Journal of Production Economics, 140(2), 614-621. https://doi.org/10.1016/j.ijpe.2011.05.029

Stonehouse, G., \& Pemberton, J. (2002). Strategic planning in SMEs-some empirical findings. Management decision, 40(9), 853-861. https://doi.org/10.1108/00251740210441072

Verreynne, M. L. (2006). Strategy-making process and firm performance in small firms. Journal of management \& organization, 12(3), 209-222. https://doi.org/10.1017/s1833367200003965

Whittington, R., Yakis-Douglas, B., Ahn, K., \& Cailluet, L. (2017). Strategic planners in more turbulent times: The changing job characteristics of strategy professionals, 1960-2003. Long Range Planning, 50(1), 108-119. https://doi.org/10.1016/j.lrp.2015.12.021

Wiesner, R., \& Millett, B. (2012). Strategic approaches in Australian SMEs: deliberate or emergent? Journal of management \& organization, 18(1), 98-122. https://doi.org/10.1017/s1833367200001097

Wiklund, J. (1999). The Sustainability of the Entrepreneurial Orientation-Performance Relationship, Frontiers of Entrepreneurship Research. Babson College. Wellesley. MA. https://doi.org/10.1177/104225879902400103

Wongsawan, N. (2009). Influences of Patterns of Strategy Formation and Performance of Medium-Sized Enterprises in the Food Manufacturing Industry in Thailand, RU Int. J, 3(1), 127-140.

\section{Copyrights}

Copyright for this article is retained by the author(s), with first publication rights granted to the journal.

This is an open-access article distributed under the terms and conditions of the Creative Commons Attribution license (http://creativecommons.org/licenses/by/4.0/). 